\title{
AUTONOMIA DA VONTADE DO PACIENTE E CAPACIDADE PARA CONSENTIR: UMA REFLEXÃO SOBRE A COAÇÃO IRRESISTÍVEL
}

Autonomy of the patient's will and capacity to consent: a reflection on the irresistible coercion

${ }^{1}$ Universidade Federal de Pernambuco. Recife/PE, Brasil.

Correspondência: Silvio Romero Beltrão. E-mail: silviorb@gmail.com.

Recebido em: 01/10/2015. Revisado em: 02/12/2015. Aprovado em: 08/12/2015. 


\section{RESUMO}

O presente trabalho pretende investigar a validade da manifestação de vontade do paciente, no momento em que o mesmo está influenciado pela dor e pelo sofrimento e necessita declarar se irá se submeter ou não a determinado tratamento. A pesquisa tem caráter interdisciplinar e se utiliza dos elementos da Teoria Geral do Direito Civil para a declaração de validade do negócio jurídico. A relação médico-paciente necessita de uma visão completa quanto aos elementos e requisitos que constituem sua validade na ordem jurídica. Como ponto de partida, analisa a relação do médico com os pacientes adeptos da religião Testemunha de Jeová para, em seguida, verificar os requisitos de validade da declaração de vontade. Investiga a manifestação da vontade como principal elemento do negócio jurídico para, no final, definir os conflitos que envolvem o estudo da autonomia da vontade e a dificuldade de solução dos casos concretos.

\section{Palavras-Chave}

Autonomia da Vontade; Coação Irresistível; Relação Médico-Paciente.

\section{ABSTRACT}

This paper aims to investigate the validity of the patient's consent from the moment that he is influenced by pain and suffering and needs to declare that he will accept a particular treatment. The research is interdisciplinary and uses the general theory of civil law for the validity declaration of the legal business. The doctor-patient relationship requires a complete overview on the elements and requirements that are to be valid in law. As a starting point, this article analyzes the doctor's relationship with Jehovah's Witness religion, to check the validity requirements of the statement of intent. It investigates the expression of the will as the main element of the transaction to define at the end those conflicts involving the study of freedom of choice and the difficulty of resolution of cases in concrete.

\section{Keywords}

Autonomy of the Will; Doctor-patient Relationship; Irresistible Coercion. 


\section{Introdução}

A intenção deste artigo é investigar a eficácia da manifestação de vontade do paciente no momento em que necessita declarar se deseja ou não realizar determinado tratamento médico, tendo por base os elementos estruturantes dos fatos jurídicos, conforme a Teoria Geral do Direito Civil, e considerando a existência de coação irresistível provocada pela dor e pelo sofrimento.

A partir da necessidade de se obter o consentimento informado do paciente, como imposto pelo Código de Ética Médica ${ }^{1}$, verifica-se que o estudo da autonomia da vontade merece uma especial atenção em face da dificuldade prática de determinação de seu conteúdo e sua validade - principalmente quando o paciente se encontra em situação de risco de morte e sua vontade é relevante na escolha do procedimento a ser realizado pelo médico.

O estudo do consentimento do paciente, neste artigo, envolve a necessidade de investigar as situações em que o médico tem o dever de indagar o paciente sobre sua vontade e, ao mesmo tempo, a obrigação de verificar se a manifestação de vontade do paciente é livre de coação interna ou externa.

As expectativas que podem surgir da atuação médica muitas vezes não se encontram suficientemente claras diante da dinâmica do consentimento informado, sendo as regras da teoria do fato jurídico necessárias para a determinação da validade do comportamento aguardado.

Assim, o presente estudo tratará do consentimento informado quanto à capacidade do paciente de compreender os fatos e as alternativas e de se autodeterminar ${ }^{2}$, bem como à validade da manifestação de vontade quando o paciente se encontrar em situação de coação interna provocada pela dor e pelo medo da morte.

\section{A recusa de tratamento médico: o exemplo da Testemunha de Jeová}

Atualmente, é reconhecida como um ato juridicamente aceitável pela doutrina da bioética a recusa de tratamento médico por questões religiosas, especialmente em relação às Testemunhas de Jeová, que não se permitem transfusão de sangue ${ }^{3,4}$.

\footnotetext{
${ }^{1}$ CONSELHOFEDERALDEMEDICINA. Resoluçãon. 1.931/2009, de 17 de setembro de 2009. Aprova o Código de Ética Médica. Disponível em: <http://www.portalmedico.org.br/resolucoes/cfm/2009/1931_2009.htm>. Acesso em: 06 set. 2009.

2PEREIRA, André Gonçalo Dias. O consentimento informado na relação médico-paciente. Coimbra: Coimbra Ed., 2004. p. 155.

${ }^{3}$ BELTRÃO, Silvio Romero. Direitos da personalidade. 2. ed. São Paulo: Atlas, 2014. p. 164.

${ }^{4} \mathrm{O}$ tema da Testemunha de Jeová também já foi objeto de artigo do autor. BELTRÃO, Silvio Romero. 0 médico e o respeito às crenças religiosas. Faculdade Marista. Disponível em: <http://www.faculdademarista.com. br/argumentum/volume1/Silvio.htm>. Acesso em: 06 set. 2014.
} 
O conflito existente entre a autonomia da vontade - fundamentada em questões religiosas - e o dever do médico de intervir para salvar a vida do paciente ainda produz controvérsias, apesar de a bioética sustentar que as crenças pessoais e convicções religiosas autorizam a recusa do tratamento médico em face do reconhecimento delas como direitos fundamentais da pessoa - inclusive, contemplados na Declaração Universal dos Direitos do Homem, em parágrafo $18^{5}$.

O fundamento para a recusa de tratamento médico por questões religiosas transcende o direito e não se explica sem a rigidez dos dogmas religiosos. Por isso, as razões religiosas para a recusa de tratamento são especiais e devem ser consideradas de modo diferente de outras razões oferecidas por pacientes ${ }^{6}$.

Wreen explica que o que torna os valores religiosos especiais

é não somente o fato de que eles são partilhados por uma comunidade, mas, o que é mais importante, que eles são incorporados pelo indivíduo na sua pessoa. Os valores religiosos, portanto, são mais intrínsecos do que outros valores partilhados, porque eles tratam do próprio significado da vida ${ }^{7}$.

Contudo, antes que o paciente tenha condições de decidir se um tratamento médico lhe é aceitável - segundo seu próprio plano de vida e com base ou não em seus valores religiosos -, ele deve ser informado sobre as possibilidades médicas de intervenção e suas recomendações. Além disso, o próprio médico deve perceber como suas recomendações afetam os valores de seu paciente.

O propósito da obrigação de prestar informações e esclarecer o paciente é dotá-lo de autonomia para poder tomar decisões com relação aos assuntos de saúde e seu tratamento de forma consciente. Assim, para que o consentimento e a recusa sejam válidos, devem ser baseados na compreensão da situação que se apresenta e devem ser voluntários, pois esse direito está baseado no princípio do respeito à autonomia.

Nesse mesmo sentido, o fato mais comum envolvendo valores religiosos é o caso das Testemunhas de Jeová, que por uma questão de consciência religiosa recusam transfusões de sangue - em razão de entenderem que a Bíblia proíbe os cristãos de manter a vida por meio da utilização de transfusões de sangue, sustentando que o

\footnotetext{
${ }^{5}$ Artigo 18: “Todo homem tem direito à liberdade de pensamento, de consciência e de religião; este direito implica liberdade de mudar de religião ou convicção, bem como a liberdade de manifestar sua religião ou convicção, só ou em comum, quer em público, quer privadamente, pelo ensino, pela prática, pelo culto e pelo cumprimento de ritos." UNICEF. Declaração Universal dos Direitos Humanos. Disponível em: <http://www.unicef.org/brazil/pt/resources_10133.htm>. Acesso em: 06 set. 2016.

${ }^{6}$ SOUZA, Zelita da Silva; MORAES, Maria Isabel Dias Morim de. A ética médica e o respeito às crenças religiosas. Simpósio de bioética. Revista do Conselho Federal de Medicina, Brasília, v. 6, n. 1, 1998. Disponível em: <http://revistabioetica.cfm.org.br/index.php/revista_bioetica/article/view/329/397>.

${ }^{7}$ Apud. Id. Ibid.
} 
abster-se de sangue é moralmente tão importante para eles quanto abster-se da idolatria ou da imoralidade sexual.

A recusa de transfusão de sangue talvez não demonstre nenhuma importância para as pessoas de outras religiões. Contudo, para as pessoas que são Testemunhas de Jeová, essa questão envolve os princípios mais fundamentais sobre os quais baseiam sua vida e, segundo elas, a recusa às transfusões constitui uma regra de conduta a ser observada, ainda que a sociedade a ignore ou menospreze.

Diante do conflito entre a autonomia de vontade do paciente e o dever de beneficência do médico, chega-se à conclusão de que, mesmo por razões religiosas, deve-se respeitar a autonomia do paciente. Não cabe ao médico desconsiderar ou minimizar os valores de ordem religiosa do paciente, ainda que diante dos mais elevados interesses profissionais.

É dever do médico aconselhar seu paciente, esclarecendo as formas de tratamento e os riscos. Caso o paciente não queira se submeter ao tratamento indicado por questões de consciência religiosa, terá o médico cumprido seu papel e, ao respeitar a autonomia do paciente, estará eticamente protegido - principalmente diante da determinação legal de que ninguém pode ser submetido, com risco de vida, a tratamento médico ou intervenção cirúrgica.

Assim, de início conclui-se que deve ser respeitada a manifestação de vontade, com base em fundamentos religiosos, para a recusa do tratamento médico.

Tendo essa questão como discutida pela bioética e direcionada à proteção da liberdade religiosa, não é o principal interesse deste artigo o estudo da Testemunha de Jeová em si mesma, mas sim o estudo da influência da dor e do sofrimento na manifestação de vontade, ao ponto de o paciente contrariar suas próprias convicções religiosas.

\section{Inversão dos problemas}

A partir do fundamento de que a Testemunha de Jeová, de forma consciente e informada, declara que não pretende se submeter a tratamento médico com transfusão de sangue, apresentamos a seguinte problemática:

Imagine-se que uma pessoa, por questões religiosas, tenha declarado antecipada e conscientemente que não pretende se submeter a tratamento cirúrgico cujo sucesso depende necessariamente de transfusão de sangue. Reiterada a necessidade de declarar seu consentimento para a transfusão de sangue, o paciente permanece em sua posição de recusa e ratifica seus valores religiosos, que pretende manter preservados. $\mathrm{O}$ médico tem conhecimento dos motivos e fundamentos da recusa do paciente e respeita sua decisão. Acontece que a saúde do paciente vai se agravando e, a cada minuto que passa, o risco de morte se encontra mais iminente. A dor e o sofrimento do paciente estão estampados em sua face, e o medo da morte passa a ser 
uma aterrorizante reflexão. Assim, diante desses fatores internos, o paciente volta-se para o médico e autoriza o procedimento cirúrgico, com transfusão de sangue.

\section{Quid juris?}

A reflexão nesse caso é necessária, pois a questão que se busca resolver é saber se o paciente, agora diante de uma coação irresistível em face da dor, do sofrimento e do medo da morte, pode modificar a declaração feita em momento de reflexão - quando, devidamente informado, teve consciência de todos os riscos e, mesmo assim, manteve sua vontade de recusar o tratamento.

Se o médico não realizar o tratamento, conforme o último desejo do paciente (nutrido pela dor) estará sendo negligente? Poderá ser responsabilizado por ter respeitado aquela primeira vontade dada com consciência e sem a coação da dor?

Por outro lado, se o médico atender ao último desejo e o paciente questioná-lo após a realização bem-sucedida do procedimento - alegando que havia declarado que, por questões religiosas, não queria realizar a transfusão de sangue e que sua última vontade estava viciada pela dor e não era consciente (não tendo validade, portanto) -, pode o médico ser responsabilizado mesmo tendo salvado a vida do paciente?

É essa a questão que se pretende responder.

Passa-se, então, aos fundamentos teóricos do consentimento informado e da autonomia do paciente com o objetivo de avaliar sua capacidade para consentir.

O consentimento informado baseia-se no princípio da autonomia, em que se devem respeitar as eleições e opiniões das pessoas quanto a seu tratamento de saúde.

Riestra ${ }^{8}$, analisando os princípios que presidem as relações entre médico e paciente, declara que existe apenas um único princípio nesta relação, que é o da autonomia, e os demais a ele aderem e somente são convocados em caso de impossibilidade de se expressar a autonomia da pessoa.

No estamos de acuerdo con que los principios éticos sean principios prima facie, sino que han de ser jerarquizados por sí mismos y no como consecuencia de que entren en colisión. Ha de haber un principio preferente y tan sólo en determinados supuestos serán de aplicación el resto. Dentro de nuestra propuesta de jerarquización el lugar preeminente lo ocupa el principio de autonomía, siendo realmente el único principio prima facie y tan sólo excepcionalmente entrarán en juego los demás teniendo entonces que hacerse la correspondiente ponderación atendiendo a las circunstancias concretas de cada caso?.

${ }^{8}$ GALLEGO RIESTRA, Sergio. El derecho del paciente a la autonomia personal y las instruciones previas: uma Nueva Realidad Legal. Navarra: Aranzadi, 2009. p. 12.

${ }^{9}$ d., loc. cit. 
A autonomia ${ }^{10}$ determina que se deva respeitar a capacidade das pessoas de se autorregularem, bem como de serem respeitadas em suas escolhas - mesmo que suas determinações entrem em conflito com as advertências de seus médicos -, contrapondo-se à concepção paternalista ${ }^{11}$.

O princípio da autonomia supõe, assim, a necessidade de se respeitarem a liberdade e autodeterminação do paciente e é considerada a própria fonte dos direitos do paciente, como uma forma de limitar os poderes dos médicos e de proteger o paciente contra os tratamentos não autorizados ${ }^{12}$.

Contudo, muitas vezes é difícil determinar os elementos que constituem uma ação autônoma do paciente, principalmente quando o mesmo está em uma situação de dor e sofrimento.

Alguns doutrinadores elegem como requisito da autonomia a ausência de um controle interno, entendida como a ausência de uma coação interna que possa controlar a vontade do paciente e que faz com que ele tome uma decisão contrária a seus próprios valores. Elegem como coação interna a dor, o sofrimento, o medo, a depressão e as enfermidades mentais. Por outro lado, Riestra ${ }^{13}$ entende a ausência de coação interna como elemento do conhecimento, da compreensão e da intencionalidade, esclarecendo que muitas vezes, coagida por alguma força interna, a pessoa pratica uma ação involuntária (sem qualquer intenção) que compreende e conhece, mas sobre a qual não tem controle.

A verdade é que a autonomia do paciente pode ser influenciada por problemas relacionados à dor, ao sofrimento e à depressão, entre outros, não sendo um caso simples de se revolver uma vez que a pessoa pode, inclusive, decidir de forma contrária a sua vontade e seus valores ${ }^{14}$.

\footnotetext{
${ }^{10}$ Pinto expressa que "a liberdade de desenvolvimento da pessoa humana compreende-se, pois, com base numa concepção do indivíduo conformador de si próprio e da sua vida segundo o seu próprio projecto espiritual". Assim, as opções religiosas do individuo devem ser respeitadas como a realização de seu projeto de vida. PINTO, Paulo Mota. O direito ao livre desenvolvimento da personalidade. Portugal - Brasil ano 2000. Boletim da Faculdade de Direito da Universidade de Coimbra, Coimbra, 1999. p. 152

${ }^{11}$ VAUGHN, Lewins. Bioethics, principles, issues and cases. 2. ed. New York: Oxford University Press, 2013. p. 180.

${ }^{12}$ GALLEGO RIESTRA, Sergio. op. cit. p. 66.

${ }^{13}$ Id., loc. cit.

14“A 64-year-old woman with MS is hospitalized. The team feels she may need to be placed on a feeding tube soon to assure adequate nourishment. They ask the patient about this in the morning and she agrees. However, in the evening (before the tube has been placed), the patient becomes disoriented and seems confused about her decision to have the feeding tube placed. She tells the team she doesn't want it in. They revisit the question in the morning, when the patient is again lucid. Unable to recall her state of mind from the previous evening, the patient again agrees to the procedure. Is this patient competent to decide? Which preference should be honored?" ETHICS in Medicine. University of Washington School of Medicine. Informed Consent: Case 1. Disponível em: <http://depts.washington.edu/bioethx/topics/consntc1.html>. (Tradução da publicação: "Uma mulher de 64 anos com esclerose múltipla está hospitalizada. A equipe médica sente que ela necessita de alimentação por sonda para lhe garantir uma nutrição adequada. A equipe questiona a paciente sobre a realização do procedimento pela manhã e ela concorda em ser entubada. Porém, à tarde (antes da colocação da sonda), a paciente se mostra desorientada e confusa sobre sua decisão. Ela diz à equipe que não quer receber a sonda. Na manhã seguinte, quando a paciente está novamente lúcida, a equipe volta a questioná-la sobre o assunto. Incapaz de se lembrar de seu estado mental na tarde anterior, a doente volta a concordar com o procedimento. A paciente é competente para decidir sobre isso? Qual decisão deve ser acatada?”)
} 


\section{Capacidade para consentir}

Evidentemente a capacidade para o exercício de direitos é posta no Código Civil com um caráter patrimonialista e negocial. Contudo, diante da necessidade de estudo da relação médico-paciente, veremos que o conceito de capacidade para consentir em um determinado tratamento médico é bem mais complexo do que uma análise da capacidade em face de uma decisão negocial ${ }^{15}$.

Mas o ponto de partida será sempre as regras de capacidade da Teoria Geral do Direito Civil. E, diante desta teoria, o critério adotado pela ordem jurídica para a validade do negócio jurídico diz respeito à perfeição da vontade manifestada, sua compatibilidade com a realidade ou a veracidade consciente de seu conteúdo ${ }^{16}$.

Esse critério busca avaliar se a vontade da pessoa não está viciada por algum fator externo ou interno que influencie a autenticidade de sua declaração, fazendo com que manifeste uma vontade que não seria verdadeiramente sua vontade se tivesse a exata noção da realidade dos fatos ou se as circunstâncias fossem diferentes ${ }^{17}$.

No caso, obrigações acessórias como a boa-fé e a equidade surgem como elementos necessários para a correta manifestação de vontade, de modo que o paciente deve estar devidamente informado de suas condições de saúde para poder tomar uma decisão mais próxima da realidade dos fatos ${ }^{18}$.

Assim, a dor e o sofrimento do paciente que autoriza a realização de transfusão de sangue é um fator interno viciante da vontade, ou um elemento do tipo que compõe o conteúdo da decisão? Ou seja, o fato de temer a morte é elemento do conteúdo da decisão de se submeter ou não ao tratamento cirúrgico, ou é uma coação que interfere na perfeita concepção dos fatos?

A perfeição da vontade manifestada constitui elemento complementar da validade do negócio jurídico ${ }^{19}$, daí que a capacidade para manifestar a vontade diante de um tratamento médico não é a mesma para a realização de uma compra e venda de um bem de consumo. A pessoa tem que ter uma capacidade especial: a de compreender todas as circunstâncias de ordem médica, todos os efeitos e consequências da doença, seus diversos tratamentos e os

\footnotetext{
${ }^{15}$ “Na verdade, a legislação tradicional referente à capacidade visa proteger mais a propriedade do que as pessoas, portanto não serve para a capacidade de tomar decisões médicas." PEREIRA, André Gonçalo Dias. op. cit., p. 18.

${ }^{16}$ MELLO, Marcos Bernardes de. Teoria do fato jurídico: plano da validade. São Paulo: Saraiva, 2004. p. 22.

${ }^{17}$ Id., loc. cit.

${ }^{18}$ Id., loc. cit.

${ }^{19}$ Id. Ibid., p. 38.
} 
riscos a eles inerentes, para poder tomar então uma decisão ausente de qualquer vício invalidante ${ }^{20}$.

A capacidade do paciente está ligada tanto a sua capacidade de fato dentro da Teoria Geral do Direito Civil ${ }^{21}$ quanto à faculdade que tem de, por si só, tomar as decisões necessárias em sua vida como sujeito de direitos e obrigações, quanto, e ainda mais, está ligada verdadeiramente a sua capacidade para tomar decisões acerca das intervenções médicas.

Assim, a capacidade para consentir nos casos que envolvem a relação médico-paciente passa a ser um conceito autonomizado em face da capacidade negocial, uma vez que o objeto da declaração de vontade tem por fundamento bens diferentes daqueles do direito patrimonial, quais sejam a vida, a saúde, a integridade física e o livre desenvolvimento da personalidade ${ }^{22}$.

Nesse sentido, as condições pessoais do paciente irão influenciar no modo com que essas informações serão prestadas, bem como na capacidade do paciente para decidir.

Podem ocorrer casos em que a pessoa possa ser considerada capaz para os atos da vida civil, mas que não tenha capacidade para expressar sua vontade em questões médicas - ou porque se encontra diante de uma dor insuportável ou porque tem um medo relevante que a impeça momentaneamente de expressar sua vontade ${ }^{23}$.

A análise dessa capacidade é realizada pelo próprio médico, diante das circunstâncias que envolvem o tratamento sugerido ao paciente.

Assim, a análise da capacidade do paciente para decidir quanto ao melhor tratamento irá depender da análise feita pelo médico caso a caso, o que envolve pacientes com capacidade e pacientes sem capacidade - e, ainda, dentre os que não possuem capacidade, alguns que realizaram manifestação de vontade adiantada e outros cuja vontade não se conhece por nunca terem se manifestado.

\footnotetext{
20“Acresce a este raciocínio de não equiparação da capacidade para consentir à capacidade negocial que a decisão sobre estes bens de natureza pessoal afecta o próprio direito geral da personalidade, pelo que, no caso de uma eventual necessidade de representação (legal) esta deve se orientar pela autodeterminação do sujeito e não pela heterodeterminação, no maior âmbito possível." PEREIRA, André Gonçalo Dias. op. cit., p. 149.

${ }^{21}$ “A esta aptidão oriunda da personalidade, para adquirir os direitos na vida civil, dá-se o nome de capacidade de direito, e se distingue da capacidade de fato, que é a aptidão para utilizá-los e exercê-los por si mesmo." PEREIRA, Caio Mario da Silva. Instituições de direito civil. 22. ed. Rio de Janeiro: Forense, 2007. v. 1, p. 263. ${ }^{22}$ PEREIRA, André Gonçalo Dias. op. cit., p. 148.

23“Por vezes é preciso levar em conta, na aferição da competência, que a vulnerabilidade do paciente, a angústia provocada pelo diagnóstico confirmador de certas patologias, dificulta assertivas categóricas, incontestáveis, quanto à racionalidade e, portanto, quanto à competência. Porém, inequívoco que algum critério de avaliação que permita apurar, com certo grau de confiabilidade ou segurança, se a pessoa sabe o que pode ocorrer, caso decida de forma equivocada, deve ser desenhado." SZTAJN, Rachel. Reflexões sobre o consentimento informado. In: AZEVEDO, Álvaro Villaça; LIGIERA, Wilson Ricardo (Coords.). Direitos do paciente. São Paulo: Saraiva, 2012. p. 184.
} 
Além do mais, quanto maior o risco do tratamento médico, maiores devem ser os cuidados com o respeito aos direitos do paciente, principalmente quanto à análise de sua capacidade para decidir ${ }^{24,25}$.

A capacidade decisória é, assim, a habilidade de entender os riscos, benefícios e alternativas e de realizar uma decisão razoável.

Mas, para que a capacidade decisória seja exercida de forma livre e plena, é necessário que a divulgação da informação seja suficientemente esclarecida.

Assim, a capacidade enquanto requisito de validade do negócio jurídico em face da relação médico-paciente adquire uma nova exigência como elemento essencial da manifestação da vontade, que tem por objeto a tomada de decisões a respeito dos cuidados de saúde e, no caso, a análise da capacidade para consentir ou recusar um tratamento médico ${ }^{26}$.

\section{A valoração da vontade do paciente e o direito ao livre desenvolvimento da personalidade como suporte jurídico constitucional da autonomia do paciente}

A vontade constitui o principal elemento do negócio jurídico, vez que os efeitos jurídicos que serão produzidos são aqueles determinados pela intenção manifestada do agente. A lei vai atribuir, juridicamente, efeitos ao fato jurídico em consonância com a vontade da pessoa que a manifesta ${ }^{27}$.

Por sua vez, para ser considerada juridicamente válida, a vontade deve ser autônoma e livre de influência que a contamine ${ }^{28}$.

\footnotetext{
24“We think that state's interest contra weakens and the individual's right to privacy grows as the degree of bodily invasion increases and prognosis dims. Ultimately there comes a point at which the individual's right overcome the state interest." 1. In re Quinlan, 70 NJ. 10, -, 355 A.2d 647, 664 (1976). (Tradução da publicação: Acreditamos que os intereses do Estado contra os mais fracos e contra o direito dos individuos à privacidade cresce na medida que o grau de invasão do corpo aumenta e o prognóstico se torna indistinto. Em última análise, chega um ponto em que o direito do indivíduo supera o interesse do Estado".)

25“Lo mismo sucede con la capacidad de razonamiento y deliberación. Pero con respecto a ambas cosas vale la idea indudable de que no existe un estándar general de competencia, de forma que pudiéramos decir que dado ciertos rasgos de una persona podemos ya declarar en términos generales si es o no es competente, sino que, muy por el contrario, el grado de competencia de cada uno depende, no sólo de quien es cada uno, sino también de los problemas que tiene ante sí, y en nuestro caso, depende de los problemas de salud sobre los que debe adoptar una decisión. No es lo mismo decidir sobre una cura trivial o un episodio leve de enfermedad conocida(la gripe común, por ejemplo) que decidir sobre una intervención de riesgo." JAVIER LAPORTA SANMIGUEL, Francisco. Algunas incógnitas del principio de autonomia personal en tratamientos médicos. In: MENDONZA BUERGO, Blanca (Coord.). Autonomia personal y decisiones médicas: cuestiones éticas y jurídicas. Pamplona: Thomson Reuters, 2010. p. 30.

${ }^{26}$ PEREIRA, André Gonçalo Dias. op. cit., p. 153.

${ }^{27}$ ASCENSÃO, José de Oliveira. Direito civil: teoria geral, acções e fatos jurídicos. Coimbra: Coimbra Ed., 1999. v. 2 , p. 22.

28“ O pressuposto do negócio jurídico é a declaração da vontade do agente, em conformidade com a norma legal, e visando a uma produção de efeitos jurídicos. Elemento específico é, então, a emissão de vontade. Se faltar, ele não se constitui. Ao revés, se existe, origina o negócio jurídico. Mas o direito não cogita de uma declaração de vontade qualquer. Cuida de sua realidade, de sua consonância com o verdadeiro e íntimo querer do agente, e de sua submissão ao ordenamento jurídico." PEREIRA, Caio Mario da Silva. op. cit., v. 1, p. 513.
} 
A vontade, para poder obrigar uma pessoa, pelo seu conteúdo, deve traduzir seu desejo e sentimento, pois, caso a declaração de vontade esteja divorciada de sua verdadeira atitude volitiva ${ }^{29}$, não será negada sua existência, mas ela poderá não produzir efeitos jurídicos.

Assim, dentro do ordenamento jurídico, para que possa ter validade a vontade deve ser juridicamente autônoma - autonomia enquanto poder que tem a pessoa de estabelecer suas próprias regras ${ }^{30}$.

A autonomia é um espaço de liberdade que é reconhecido à pessoa para desenvolver sua vida de acordo com seus interesses e valores ${ }^{31}$. Como o Estado não pode prever formalmente todas as situações jurídicas que envolvem as relações humanas em seu cotidiano nem pode fixar, caso a caso, as múltiplas consequência jurídicas, remete para a própria pessoa, a partir da autonomia da vontade, o poder de impor suas próprias regras, ou seja, o poder de dar-se um ordenamento ${ }^{32,33}$.

Assim, conforme Menezes Cordeiro, "a autonomia privada deixa à liberdade humana a prática de factos jurídicos, portanto de ocorrências que, por integrarem previsões normativas, desencadeiam efeitos de Direito" ${ }^{34}$.

Ora, a vontade livre e autônoma da pessoa, dentro do sistema jurídico, produzirá efeitos na forma e na medida determinadas por esta mesma vontade, caracterizando o negócio jurídico ${ }^{35}$.

A atuação do paciente em relação ao médico deve ser livre e autônoma para poder determinar o conteúdo e a extensão dos efeitos que pretende que o negócio jurídico produza em relação ao tratamento médico.

Nesse sentido, o Código de Ética Médica brasileiro determina que é necessário obter o consentimento do paciente para a realização da intervenção médica, o que representa a necessidade de obter a declaração de vontade do paciente quanto ao tratamento a que será submetido levando em consideração a liberdade da pessoa para desenvolver sua personalidade.

\footnotetext{
${ }^{29}$ PEREIRA, Caio Mario da Silva. op. cit., v. 1.

30“Autonomia é o poder de dar-se um ordenamento. Neste sentido substancial, a autonomia provada significa que a ordem jurídica global admite que os particulares participem da construção da sua própria ordem jurídica, nos quadros embora da ordem jurídica global. Desde que a esfera jurídica de cada um não resulte de uma demarcação autoritária, antes se admita na sua modelação a intervenção dos próprios particulares dela titulares, há autonomia." (ASCENSÃO, José de Oliveira. op. cit., p. 66).

31“"Em termos amplos, ela equivale ao espaço de liberdade reconhecido a cada um dentro da ordem jurídica: engloba tudo quanto as pessoas podem fazer, num prisma material ou num prisma jurídico." CORDEIRO, Antônio Menezes. Tratado de direito civil português: parte geral. 3. ed. Coimbra: Almedina, 2005. v. 1, t. 1, p. 391.

${ }^{32}$ ASCENSÃO, José de Oliveira. op. cit., p. 66

${ }^{33}$ CORDEIRO, Antônio Menezes. op. cit, p. 392.

${ }^{34}$ Id., loc. cit.

${ }^{35}$ Id., loc. cit.
} 
A autonomia da vontade como requisito de validade do negócio jurídico e princípio do direito comum tem por base a própria noção da pessoa em desenvolvimento, visto que a pessoa não é um projeto acabado, conforme ensina Ascensão: ela tende a se aperfeiçoar, o que consiste em uma atuação individual e autônoma que se realiza na valoração da liberdade ${ }^{36}$.

Garantir a liberdade da pessoa significa permitir que esta mesma pessoa possa desenvolver sua personalidade de modo que sua atuação seja livre e autônoma ${ }^{37}$.

A pessoa é um ser em construção que não se realiza de forma pré-determinada ou herdada, mas que, na realidade, se molda pela própria ideia de autonomia eliberdade ${ }^{38}$.

Daí que o reconhecimento da autonomia da vontade do paciente é consequência do direito ao livre desenvolvimento da personalidade, por sua vez resultado da autonomia que a pessoa tem através da proteção das liberdades, possibilitando sua atuação segundo seus desígnios e sua vontade ${ }^{39}$.

Para além da dimensão da tutela da personalidade em face do conteúdo do livre desenvolvimento da personalidade, há também a dimensão que protege a liberdade geral de ação da pessoa, ou seja, uma liberdade de comportamento diante da dinâmica da vida, que lhe permite um campo de atuação próprio ${ }^{40}$.

A liberdade consagrada como dimensão do livre desenvolvimento da personalidade é uma liberdade limitada pela ordem pública, tal qual como disposto no direito alemão, "dentro dos limites da ordem jurídica e dos bons costumes, de fazer tudo que não prejudique a outrem"41.

A consagração dessa dimensão do desenvolvimento da personalidade visa a garantir um espaço de individualidade da pessoa em que ela possa agir de forma autônoma e se autodeterminar, assegurando-lhe a liberdade de construir seu próprio projeto de vida.

\footnotetext{
${ }^{36}$ ASCENSÃO, José de Oliveira. op. cit., p. 98.

37 “A garantia do espaço de actuação de cada um concentra-se essencialmente na ideia de liberdade: porque só em liberdade o homem pode desenvolver a sua personalidade. As várias liberdades asseguram o exercício de autonomia necessário ao desenvolvimento humano." Id. Ibid. p. 98).

38“A liberdade de desenvolvimento da pessoa humana compreende-se, pois, com base numa concepção "do indivíduo conformador de si próprio e da sua vida segundo o seu próprio projecto espiritual (plastes et fictor). A forma de realização da personalidade humana não é algo pré-determinado, que se receba por atribuição, herança, situação num dado momento ou classe, ou por imposição ou dádiva a partir de um determinado padrão ou modelo. Trata-se, antes, de algo que auto-institui ou constrói, segundo o seu próprio projeto, determinado a partir da própria pessoa, como centro de decisão autônoma." PINTO, Paulo Mota. op. cit., p. 150.

39“"Ou seja, a personalidade humana não reveste um carácter estático, mas dinâmico, protegendo-se por isso mesmo também o direito ao desenvolvimento da própria personalidade (com a sua inerente adaptabilidade ambiental e sócio-econômica) e sufragando-se a ideia de que tanto a essência como a existência do homem, enquanto determinantes da sua personalidade, merecem idêntica proteção legal." SOUSA, Rabindranath Valentino Aleixo Capelo de. O Direito Geral da Personalidade. Coimbra: Coimbra Editora, 1995. p. 117.

${ }^{40}$ PINTO, Paulo Mota. op. cit. p. 198.

${ }^{41}$ Id. Ibid., p. 199.
} 


\section{A interpretação da vontade}

A partir da ideia de que a natureza jurídica da relação médico-paciente é de um negócio jurídico - que pode se expressar pela forma contratual, por uma declaração unilateral de vontade ou pela gestão de negócios -, a vontade da pessoa passa a ser o núcleo essencial desse negócio jurídico ${ }^{42,43}$.

A relação médico-paciente necessita da convergência entre a atuação da vontade das partes e o ordenamento jurídico para que o negócio jurídico seja válido e produza efeitos ${ }^{44}$.

Quando a vontade declarada pelo paciente se forma sobre uma motivação conforme com a realidade e a liberdade, os efeitos jurídicos contidos na declaração serão válidos, pois representam a valoração de sua autonomia. Contudo, pode o paciente por causas diversas expressar uma vontade que não corresponda a sua vontade real, provocando uma divergência que pode influenciar na validade do negócio jurídico envolvendo o médico e o paciente ${ }^{45}$.

Por isso, a compreensão da vontade do paciente é importante para a validade do tratamento médico. O paciente está tomado pela dor, pelo medo, pelo sofrimento, pelas várias circunstâncias que envolvem o tratamento médico. Todos esses fatores podem ter influência na construção da vontade do paciente, e as informações que ele receber do médico, bem como seus valores existenciais, têm relevância e importância para que possa formar sua convicção ${ }^{46}$.

Assim, a relação médico-paciente não foge ao sistema da declaração negocial constitutivo do negócio jurídico, em que normalmente se destacam a declaração propriamente dita, como elemento externo, e a vontade, como elemento interno ${ }^{47}$.

Desta forma, a vontade interior como pressuposto do negócio jurídico deve ser exteriorizada, através de sua declaração, de modo que o mundo exterior possa reconhecê-la.

A doutrina se preocupa com o estudo da vontade a partir dessas duas perspectivas, pois são aspectos importantes para a determinação da eficácia da declaração negocial na relação médico-paciente.

\footnotetext{
${ }^{42}$ PINTO, Carlos Alberto Mota. Teoria geral do direito civil, 4. ed. Coimbra: Coimbra Ed., 2012. p. 413.

43"O conteúdo do negócio jurídico é a regulação que nele é posta em vigor, no âmbito da autonomia privada." VASCONCELOS, Pedro Paes de. Teoria geral do direito civil. 3. ed. Coimbra: Almedina, 2005. p. 417.

${ }^{44}$ PEREIRA, André Gonçalo Dias. op. cit., p. 480.

${ }^{45}$ PINTO, Carlos Alberto Mota. op.cit. p. 458.

46“"Os problemas decisivos para o efeito de determinar o conceito de declaração negocial - corresponde aos dados do sistema - são o da divergência entre a vontade e a declaração, o dos vícios da vontade, o da interpretação da declaração negocial, etc." Id. Ibid. p. 414.

${ }^{47}$ Id. Ibid. p. 419.
} 
A construção da vontade dentro da perspectiva psíquica impõe ao paciente uma deliberação ${ }^{48}$, uma análise interior, de acordo com as informações que venha a receber do médico e as circunstâncias que envolvem o tratamento médico; sua validade e eficácia dependerão que a declaração exteriorizada esteja em consonância com o íntimo querer da pessoa e não se traduza, em face das circunstâncias, em uma falsa noção da realidade.

Por isso, não se deve afastar o fato de que, para manifestar sua vontade, o paciente recebe desde logo os estímulos provocados pelos sintomas do mal que lhe atinge, as aflições, as dores, os sofrimentos que integram as circunstâncias em que sua vontade é expressa.

E, mesmo ainda estando sujeito a esses estímulos interiores, o paciente deve receber do médico as informações necessárias para compreender a doença e os sintomas que lhe afligem, bem como a forma ou formas de tratamento daquela doença e o prognóstico de sucesso e cura.

Diante desses estímulos interiores, em relação aos quais têm relevância as informações prestadas pelo médico, as circunstâncias do tratamento, as dores, o sofrimento, a cultura e os valores que a pessoa possui, o paciente fará sua deliberação ponderando o que imagina ser melhor para si naquele momento, para ao final elaborar sua vontade.

Elaborada a vontade, surge o terceiro momento, em que essa mesma vontade é manifestada para o exterior, sendo reconhecida pelo médico.

Ora, a validade e eficácia da declaração do paciente irão depender de diversos fatores: se o paciente tem a exata noção da realidade dos fatos, se foi devidamente informado, se é capaz, se as dores não tenham viciado sua vontade - enfim, se a vontade exteriorizada está em sintonia com a vontade interior.

Contudo, caso o médico não tenha prestado as informações necessárias e, ainda, se o paciente não tiver capacidade de compreender os detalhes do tratamento, de modo que isso possa influenciar sua capacidade para decidir e a exata noção da realidade seja perdida, a manifestação de vontade exteriorizada pelo paciente poderá não ser válida, nem efica ${ }^{49}$.

\footnotetext{
48“No campo puramente psíquico distinguem-se três momentos: o da solicitação, o da deliberação e o da ação. Primeiramente os centros cerebrais recebem o estímulo do meio exterior; em seguida, mais ou menos rapidamente, ponderam nas conveniências e resolvem como proceder; e finalmente reage a vontade à solicitação." PEREIRA, Caio Mario da Silva. op. cit., v. 1, p. 481.

49،O negócio jurídico apresenta-se como uma manifestação da autonomia privada; nessa medida, ele deve corresponder à vontade autónoma das pessoas ou mais não será do que um simulacro de autonomia: o Direito - sendo, como é, uma Ciência - não pode assentar em equívocos ou em ficções." CORDEIRO, Antônio Menezes. op. cit., v. 1, t. 1, p. 542.
} 
É certo que em um tratamento médico não se deve excluir a possibilidade de dor, de sofrimento, de medo, bem como a compreensão de que a liberdade e o discernimento não são absolutos, nem mesmo perfeitos e ilimitados, devendo a declaração ser analisada a partir do conceito médio de uma pessoa normal, diante dessas mesmas circunstâncias ${ }^{50}$.

Para a validade da manifestação da vontade, devem-se acrescentar ao sentido declarado pelo paciente todas as circunstâncias que envolvem seu tratamento, como forma de auxiliar a correta compreensão de sua vontade e como elemento essencial para a busca de seu desejo interior.

A busca pela vontade interior, de modo a tentar chegar a uma vontade mais próxima da realidade interna, depende das circunstâncias que determinaram a manifestação da vontade do paciente para a realização do tratamento, pois passam a ter importância seus valores e sua cultura, seu estado de hipossuficiente em relação ao médico, entre outras circunstâncias possíveis.

Assim, a valoração da vontade do paciente integra uma lógica de respeito ao desenvolvimento de sua autonomia pessoal, seu corpo, sua saúde e sua vida, valores estes fundados no princípio da dignidade da pessoa humana, que alteram a função do negócio jurídico médico-paciente em relação ao negócio jurídico patrimonial ${ }^{51,52}$.

Desta forma, a busca pela vontade interior do paciente deve ser uma obstinação do médico, pois as expectativas do paciente em relação a seu bem-estar envolvem, entre outros aspectos, seus valores, sua cultura e seus sentimentos. Assim, o respeito à vontade do paciente interessa a garantia de seu livre desenvolvimento da personalidade ${ }^{53}$.

\footnotetext{
50“O negócio jurídico, como acto de autonomia privada e como acção que gera e põe em vigor um regulamentação interprivada, com o seu carácter criador de direito, supõe e exige de parte dos seus autores liberdade e discernimento. Não existem, porém, liberdade e discernimento que sejam absolutos, que sejam perfeitos e ilimitados. A autonomia privada contenta-se com a liberdade e o discernimento normais, isto é, que são próprios das pessoas normais, das pessoas comuns. Para celebrar um negócio jurídico não é, por isso, necessário estar completamente livre de constrangimentos. A própria vida em sociedade, com as suas circunstâncias, o contacto social e o contacto com a natureza, constrangem e limitam a liberdade das pessoas." VASCONCELOS, Pedro Paes de. Teoria geral do direito civil, cit., p. 491.

51“ 0 negócio jurídico que se mantenha sem vontade real não é já um verdadeiro negócio mas, antes, uma manifestação de confiança tutelada; tal tutela exige, desde logo, toda uma série de dispositivos legais que a facultem e que não se confundem com a autonomia privada." CORDEIRO, Antônio Menezes. op. cit., v. 1, t. 1, p. 542.

52“A autonomia privada, no exercício do direito de personalidade, tem dois aspectos principais: o da iniciativa na defesa da personalidade e a da auto-vinculação à sua limitação ou compressão. No primeiro dos referidos aspectos, o titular é livre de exercer o seu direito ou de se abster de o fazer. Num caso de ofensa corporal, a vítima pode abster-se de se defender e até de recorrer aos meios públicos de defesa (policia, tribunais), pode, por exemplo, 'dar a outra face'. É livre de escolher a sua atitude perante a ofensa. Esta liberdade é reveladora da autonomia do titular que pode decidir, só por si e livremente, sobre o exercício do direito, sem estar vinculado heteronomamente. Num outro exemplo, o doente pode não querer ser tratado." VASCONCELOS, Pedro Paes de. Direitos da personalidade. Coimbra: Almedina, 2006. p. 153.

${ }^{53}$ VASCONCELOS, Pedro Paes de. Teoria geral do direito civil, cit., p. 74.
} 


\section{Considerações finais: Ulisses e o canto das sereias}

Para melhor ilustração do problema - conflito entre a vontade real e a vontade declarada em face da coação interna da dor e do sofrimento -, faz-se necessária uma leitura de passagem da obra "Odisseia" ${ }^{54}$.

A “Odisseia”, de Homero, narra a história de Ulisses, rei da ilha de Ítaca que se juntou a outros gregos na guerra de Troia. Dentre as várias aventuras de Ulisses, há o episódio do canto das sereias, em que navegava próximo a Capri, uma ilha rochosa cheia de sereias, tentando voltar para casa.

Sabia-se que o canto das sereias tinha o poder de encantar os homens, que, em busca de sua beleza, se aproximavam das pedras e chocavam o navio contra os rochedos, levando à morte todos que estavam a bordo.

Ulisses, então, determinou que todos os marinheiros tapassem os ouvidos com cera enquanto passassem perto da ilha. Mas Ulisses não tapou seus próprios ouvidos: pediu para ser amarrado ao mastro da embarcação e para que não o desamarrassem nem o libertassem em circunstância alguma, mesmo que ele assim ordenasse.

Conta o texto que, ao passar próximo à ilha e ouvir as sereias, Ulisses gritava desesperadamente para ser desamarrado, mas seus homens não podiam escutá-lo e, além de tudo, tinham ordens expressas para não obedecê-lo.

O que essa passagem da "Odisseia" nos ensina no caso concreto em que a Testemunha de Jeová, compelida pela dor, determina que lhe façam transfusão de sangue? É que, mesmo tendo a autoridade de determinar uma atuação diversa de sua vontade real, conhecida e refletida, a pessoa não pretende que tal vontade seja obedecida quando estiver viciada pela dor ou pelo sofrimento.

A vontade viciada pela dor e pelo sofrimento não deve prevalecer quando a pessoa -antecipadamente de forma informada, refletida e com fundamento em seus valores sociais e espirituais - expõe um determinado comportamento. O risco da vontade não refletida é causar um mal maior do que o bem momentâneo desejado pelo impulso da dor.

Faz-se necessário relembrar que a maior parte das religiões declara a existência da vida após a morte, impondo uma visão eterna da vida, através do sofrimento e da resignação $0^{55}$.

Apesar disso, entendo que essa passagem da "Odisseia" não é suficiente para responder a todas as questões postas no dia a dia da medicina. A vida da pessoa

\footnotetext{
${ }^{54}$ AS SEREIAS e a Odisséia - Como resistir ao “Canto da Sereia” conforme Homero. Postado há 18th Nov. 2012 por Marcus Azen. Disponível em: <http://eradaincerteza.blogspot.com.br/2012/11/as-sereias-naodisseia-de-homero-como.html>.

${ }^{55}$ ARAÚJO, Fernando. A procriação assistida e o problema da santidade da vida. Coimbra: Almedina, 1999. p. 121.
} 
não pode ser previamente rotulada e descartada. É necessária a apreciação de cada caso individualmente.

Parece que também aqui os médicos não poderão livrar-se do peso de sua responsabilidade através de apelos para uma intervenção legislativa, para uma definição de deveres ancorada em princípios ou em evidências: mesmo com todas as suas falhas, não parece haver sucedâneo satisfatório para o "bedside rationing", para a ponderação casuística dos valores em jogo que a si mesma sedimenta como processo de descoberta de critérios de decisão ${ }^{56}$.

Há situações que demonstram que o mais aceitável é não termos uma indicação prévia dos princípios decisórios, diante da complexidade e da variedade de situações que se apresentam perante o médico e que desaconselham as fórmulas prontas, dando-se preferência a um pragmatismo qualificado que atribui ao médico a avaliação autônoma dos benefícios e consequências de sua intervenção, diante da funcionalidade das variáveis e seus valores ${ }^{57}$.

$\mathrm{Na}$ manifestação da vontade do paciente sempre ficará a pergunta: onde começa o medo e a ameaça da dor? Até onde podem a dor e o sofrimento influenciar a vontade real da pessoa?

Os impulsos da dor podem ser sentidos de forma diversa por cada pessoa ${ }^{58}$; a pessoa pode se sentir constrangida em certo momento e, em outro, sua atuação pode ser indiferente.

Assim, sempre restará a indagação: apesar da coação da dor, ainda haverá vontade? O que deve o médico fazer? Suprimir a vontade do paciente? Mas tal atitude pode, em certos casos, ser desfavorável ao próprio paciente.

Ao fim, caberá ao médico avaliar o quanto a dor e o sofrimento podem influenciar na vontade do paciente, e até onde pode ser suprida a vontade desse paciente.

Não haverá respostas claras longe das circunstâncias do caso em concreto. Quando o paciente manifesta sua vontade viciada pela dor e pelo sofrimento, para além do conflito de vontades há a necessidade do respeito a sua humanidade, em que o valor da vida sempre estará em jogo e há a possibilidade constante de o médico estar diante de dois extremos: o da morte e o do prolongamento inútil da vida ${ }^{59}$.

\footnotetext{
${ }^{56}$ ARAÚJO, Fernando. op. cit., p. 121.

${ }^{57}$ Id. Ibid., p. 170.

${ }^{58}$ CORDEIRO, Antônio Menezes. Tratado de direito civil português: parte geral: negócio jurídico. 4. ed. Coimbra: Almedina, 2014. v. 2, p. 830.

59"Há tanta probabilidade de terminar cedo demais como de terminar tarde demais o tratamento médico que nos liga artificialmente a vida". ARAÚJO, Fernando. op. cit., p. 173.
} 


\section{Referências}

ARAÚJO, Fernando. A procriação assistida e o problema da santidade da vida. Coimbra: Almedina, 1999.

AS SEREIAS e a Odisséia - Como resistir ao "Canto da Sereia" conforme Homero. Postado há 18th Nov. 2012 por Marcus Azen. Disponível em: <http://eradaincerteza.blogspot.com. br/2012/11/as-sereias-na-odisseia-de-homero-como.html $>$.

ASCENSÃO, José de Oliveira. Direito civil: teoria geral, acções e fatos jurídicos. Coimbra: Coimbra Ed., 1999. v. 2.

BELTRÃO, Silvio Romero. Direitos da personalidade. 2. ed. São Paulo: Atlas, 2014.

O médico e o respeito às crenças religiosas. Faculdade Marista. Disponível em: $<\mathrm{http}: / /$ www.faculdademarista.com.br/argumentum/volume1/Silvio.htm>. Acesso em: 06 set. 2014.

CORDEIRO, Antônio Menezes. Tratado de direito civil português: parte geral. 3. ed. Coimbra: Almedina, 2005. v. 1, t. 1.

Tratado de direito civil português: parte geral: negócio jurídico. 4. ed. Coimbra: Almedina, 2014. v. 2.

ETHICS in Medicine. University of Washington School of Medicine. Informed Consent: Case 1. Disponível em: <http://depts.washington.edu/bioethx/topics/consntc1.html >.

GALLEGO RIESTRA, Sergio. El derecho del paciente a la autonomia personal y las instruciones previas: uma Nueva Realidad Legal. Navarra: Aranzadi, 2009.

JAVIER LAPORTA SANMIGUEL, Francisco. Algunas incógnitas del principio de autonomia personal en tratamientos médicos. In: MENDONZA BUERGO, Blanca (Coord.). Autonomia personal y decisiones médicas: cuestiones éticas y jurídicas. Pamplona: Thomson Reuters, 2010.

MELLO, Marcos Bernardes de. Teoria do fato jurídico: plano da validade. São Paulo: Saraiva, 2004.

PEREIRA, André Gonçalo Dias. O consentimento informado na relação médico-paciente. Coimbra: Coimbra Ed., 2004.

PEREIRA, Caio Mario da Silva. Instituições de direito civil. 22. ed. Rio de Janeiro: Forense, 2007. v. 1.

PINTO, Carlos Alberto Mota. Teoria geral do direito civil, 4. ed. Coimbra: Coimbra Ed., 2012.

PINTO, Paulo Mota. O direito ao livre desenvolvimento da personalidade. Portugal - Brasil ano 2000. Boletim da Faculdade de Direito da Universidade de Coimbra, Coimbra, 1999.

SOUSA, Rabindranath Valentino Aleixo Capelo de. O Direito Geral da Personalidade. Coimbra: Coimbra Editora, 1995. 
SOUZA, Zelita da Silva; MORAES, Maria Isabel Dias Morim de. A ética médica e o respeito às crenças religiosas. Simpósio de bioética. Revista do Conselho Federal de Medicina, Brasília, v. 6, n. 1, 1998. Disponível em: <http://revistabioetica.cfm.org.br/index.php/revista_bioetica/ article/view/329/397>.

SZTAJN, Rachel. Reflexões sobre o consentimento informado. In: AZEVEDO, Álvaro Villaça; LIGIERA, Wilson Ricardo (Coords.). Direitos do paciente. São Paulo: Saraiva, 2012.

UNICEF. Declaração Universal dos Direitos Humanos. Disponível em: <http://www.unicef. org/brazil/pt/resources_10133.htm>. Acesso em: 06 set. 2016.

VASCONCELOS, Pedro Paes de. Direitos da personalidade. Coimbra: Almedina, 2006. Teoria geral do direito civil. 3. ed. Coimbra: Almedina, 2005.

VAUGHN, Lewins. Bioethics, principles, issues and cases. 2. ed. New York: Oxford University Press, 2013.

Silvio Romero Beltrão - Pós-Doutor em Direito pela Faculdade de Direito da Universidade de Lisboa; Doutor em Direito pela Universidade Federal de Pernambuco (UFPE), mestre em Direito pela UFPE. Professor Adjunto da Faculdade da UFPE. Recife/PE, Brasil. E-mail: silviorb@gmail.com. 